\title{
The Onset of Dental Erosion Caused by Food and Drinks and the Preventive Effect of Alkaline Ionized Water
}

\author{
Tsutomu Sato ${ }^{1,2, *}$, Yoshitaka Fukuzawa ${ }^{3}$, Satoshi Kawakami ${ }^{1}$, Megumi Suzuki ${ }^{4}$, Yoshinori Tanaka ${ }^{1}$, \\ Hayato Terayama ${ }^{1}$ D and Kou Sakabe ${ }^{1}$
}

1 Division of Basic Medical Science, Tokai University School of Medicine, Isehara 259-1193, Japan; kawakamis@tsc.u-tokai.ac.jp (S.K.); ksato21@aol.com (Y.T.); terahaya@tokai-u.jp (H.T.); sakabek@tokai-u.jp (K.S.)

2 Division of Basic Research, Functional Water Research Laboratory, Louis Pasteur Center for Medical Research, Kyoto 606-8225, Japan

3 Aichi Medical Preemptive and Integrative Medicine Center, Aichi Medical University Hospital, Nagakute 480-1103, Japan; yofuku@aichi-med-u.ac.jp

4 Department of Dental Hygiene, The Nippon Dental University College at Tokyo, Tokyo 102-0071, Japan; megumi-t@tandai.ndu.ac.jp

* Correspondence: b-sato2@tsc.u-tokai.ac.jp; Tel.: +81-463-93-1121 (ext. 4303)

check for updates

Citation: Sato, T.; Fukuzawa, Y.; Kawakami, S.; Suzuki, M.; Tanaka, Y.; Terayama, H.; Sakabe, K. The Onset of Dental Erosion Caused by Food and Drinks and the Preventive Effect of Alkaline Ionized Water. Nutrients 2021, 13, 3440. https://doi.org/ $10.3390 /$ nu13103440

Academic Editor:

Kamyar Kalantar-Zadeh

Received: 13 August 2021

Accepted: 25 September 2021

Published: 28 September 2021

Publisher's Note: MDPI stays neutral with regard to jurisdictional claims in published maps and institutional affiliations.

Copyright: (c) 2021 by the authors. Licensee MDPI, Basel, Switzerland. This article is an open access article distributed under the terms and conditions of the Creative Commons Attribution (CC BY) license (https:/ / creativecommons.org/licenses/by/ $4.0 /)$.

\begin{abstract}
In recent years, the incidence of dental erosion caused by the ingestion of acidic foods and drinks, including sports drinks, has been increasing in Japan and elsewhere. Therefore, the problems associated with this injury can no longer be ignored in dental clinical practice. The ingestion of these foods and drinks is important from the viewpoint of overall health and disease prevention. For example, fermented foods, such as Japanese pickles, enhance the nutritional value of foodstuffs and promote the absorption of nutrients into the body, and sports drinks are useful for preventing heat stroke and dehydration. Therefore, eliminating these intakes is not a viable solution. In this paper, we outline the mechanism of dental erosion caused by acidic beverages and also describe the effectiveness of alkaline ionized water (AIW) at preventing acid erosion. Given the fact that the complete elimination of acidic beverage consumption is highly unlikely, remedies such as the use of alkaline ionized water (AIW) may be helpful.
\end{abstract}

Keywords: acidic foods and drinks; nutrients; dental erosion; alkaline ionized water; demineralization; oral flora

\section{Dental Caries and Acid Erosion}

Dental caries is an infectious disease caused by cariogenic bacteria that inhabit the oral cavity, and its pathology involves the demineralization of dental hard tissues by the acids produced by cariogenic bacteria [1]. Furthermore, since the occurrence of dental caries is related to lifestyle-related factors, such as diet and tooth brushing habits, it can also be characterized as a lifestyle-related disease. The prevalence of dental caries in Japan is still high compared to other industrialized countries, but it is gradually decreasing. Similar to dental caries, dental acid erosion is a disease that causes demineralization of the teeth. Acid erosion is a disease in which the enamel formed on the tooth surface undergoes demineralization due to organic substances present in the environment, especially acids, and has been known as an occupational disease for a long time [2]. In other words, there are no bacterial acids involved in the development of dental acid erosion. Dental erosion is found in workers in manufacturing industries that have long used or produced acids, such as sulfuric acid, nitric acid, and hydrochloric acid. It is also seen in workers who are employed in factories that produce dyes and gunpowder, metal plating, storage batteries, and fertilizers. Teeth that have been decalcified by chemical acids are called erosive teeth. On the other hand, in recent years, apart from occupational dental erosion, epidemiological surveys in Japan and overseas have revealed that the incidence of dental erosion caused by 
the intake of highly acidic foods and drinks has been increasing. Recently, Japan has been reporting higher incidences of dental erosion among athletes, infants, and the elderly due to their frequent consumption of sports drinks for dehydration purposes and to prevent heat stroke [3]. We measured the $\mathrm{pH}$ of several types of beverages that are often consumed in Japan [4] and observed that most were below $\mathrm{pH}$ 5.6-5.7, which is the $\mathrm{pH}$ at which enamel is decalcified [5-8] (Table 1).

Table 1. $\mathrm{pH}$ values of various beverages [4].

\begin{tabular}{cc}
\hline Beverage & pH \\
\hline Cola & 2.2 \\
Sports drink & 3.3 \\
Orange juice & 3.7 \\
Yoghurt drink & 3.9 \\
Barley tea (Japanese mugi cha) & 6.1 \\
\hline
\end{tabular}

The recent increased consumption of acidic foods and drinks is a major health concern. For example, fermented foods enhance the nutritional value of foodstuffs and promote the absorption of nutrients, and sports drinks are useful for preventing heat stroke. Therefore, it is not appropriate to avoid these intakes. In this paper, we describe the dental erosion caused by acidic beverages and discuss the effectiveness of preventing erosion with alkaline ionized water (AIW).

\section{Alkaline Ionized Water}

Alkaline ionized water (AIW) is generated by electrolyzing tap water at the cathode of a household electrolyzed water generator (alkaline ionized water conditioner) that has JIS (Japanese Industrial Standards; JIS T2004) approval [9]. It is weakly alkaline (pH 9-10) water. AIW has been confirmed to be effective at improving gastrointestinal symptoms [10] and has been approved for drinking by the Japanese Ministry of Health, Labor and Welfare. We have found that AIW is also useful in maintaining oral health [11], and in this paper, we describe the usefulness of AIW ( $\mathrm{pH}$ 9.5) in the prevention of dental erosion of teeth based on the results of our previous research.

\section{Measuring Enamel Surface $\mathrm{pH}$}

The measurement of saliva $\mathrm{pH}$ is a useful test for assessing the risk of enamel demineralization and is widely used [12]. However, due to the buffer capacity of saliva [13-15], it is possible that its $\mathrm{pH}$ does not always reflect the $\mathrm{pH}$ of the enamel surface (Es $\mathrm{pH})$. Therefore, we have established a system for measuring the Es $\mathrm{pH}$ [16]. The Es $\mathrm{pH}$ was measured using a continuous measurement system consisting of an oral $\mathrm{pH}$ antimony electrode (model: SP-Sb-052, Chemical Equipment Co., Ltd. Tokyo, Japan), a pH meter (model: PH-201Z, Chemical Equipment Co., Ltd.), a recorder (model: VR-71, T \& D Co., Ltd. Nagano, Japan), a USB serial converter (Latoc System Co., Ltd. Osaka, Japan), and a personal computer (Figure 1). The measurement site of the $\mathrm{Es} \mathrm{pH}$ was the buccal side of the left molar of the maxilla, and the measurements were performed at rest and before and after ingesting an acidic beverage and AIW. The Es pH was measured once in each experiment. When ingesting a beverage, the electrode is not initially in contact with the enamel surface. The electrode is brought into contact with the tooth surface quickly after intake, which takes about $10 \mathrm{~s}$. Figures 2-6 show the measurement results of the Es $\mathrm{pH}$, and the values are presented as continuous data for convenience. The experiment was conducted $3 \mathrm{~h}$ after brushing following lunch. As a result of measuring the Es $\mathrm{pH}$ of resting subjects $(\mathrm{N}=5)$ for 5 min continuously, the $\mathrm{pH}$ did not always show a constant value but showed a change in the range of about 0.1 to 0.3 . Therefore, in this experiment, measurements were taken continuously for $5 \mathrm{~min}$, and the median of the minimum and maximum values observed during this period was taken as the $\mathrm{Es} \mathrm{pH}$ at rest. As a result, individual differences were observed in the Es pH, and the median was in the range of 5.2-5.9 (Table 2). Figure 2 shows 
the measurement results of the Es $\mathrm{pH}$ of subject ID 5 at rest. At the measurement time of $5 \mathrm{~min}$, the $\mathrm{pH}$ fluctuated between approximately 5.7 and 6.1 .

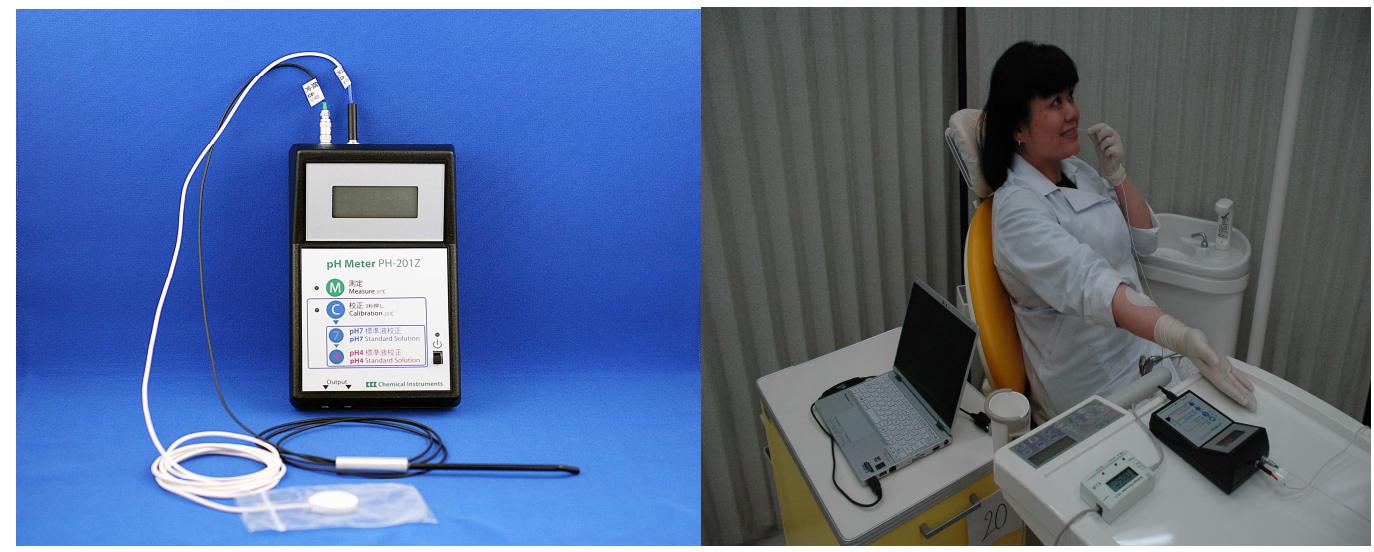

Figure 1. Measurement of enamel surface $\mathrm{pH}$ [13]. Left: $\mathrm{pH}$ antimony electrode connected to $\mathrm{pH}$ meter. Right: Photograph taken during enamel surface $\mathrm{pH}$ measurement.

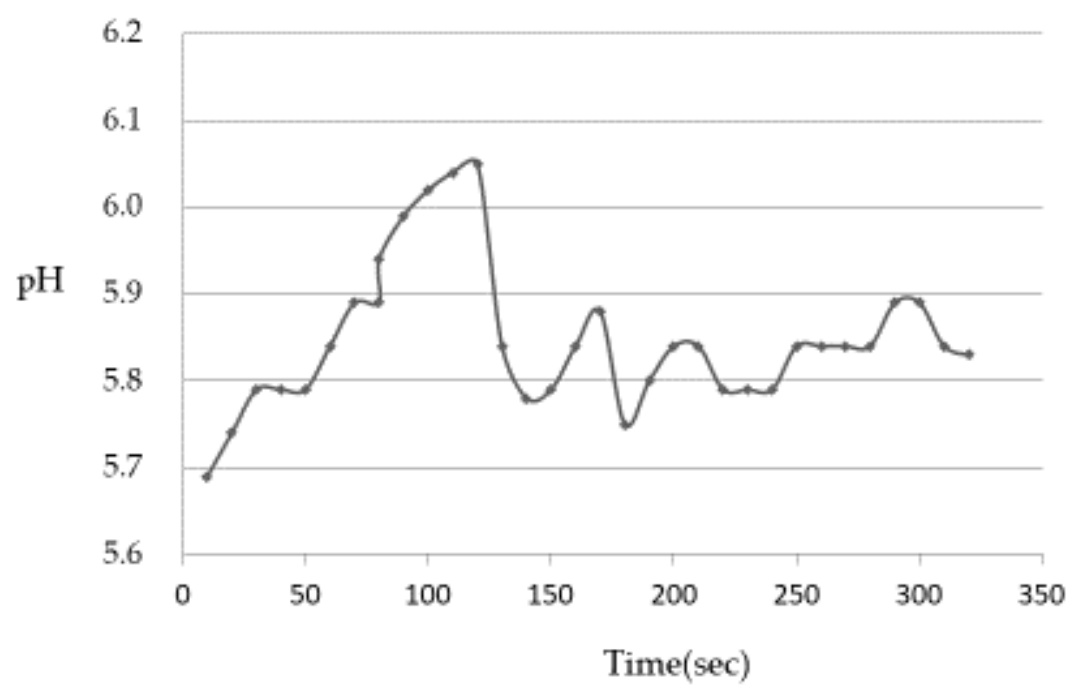

Figure 2. Changes in Es pH at rest (Subject ID:5) [17].

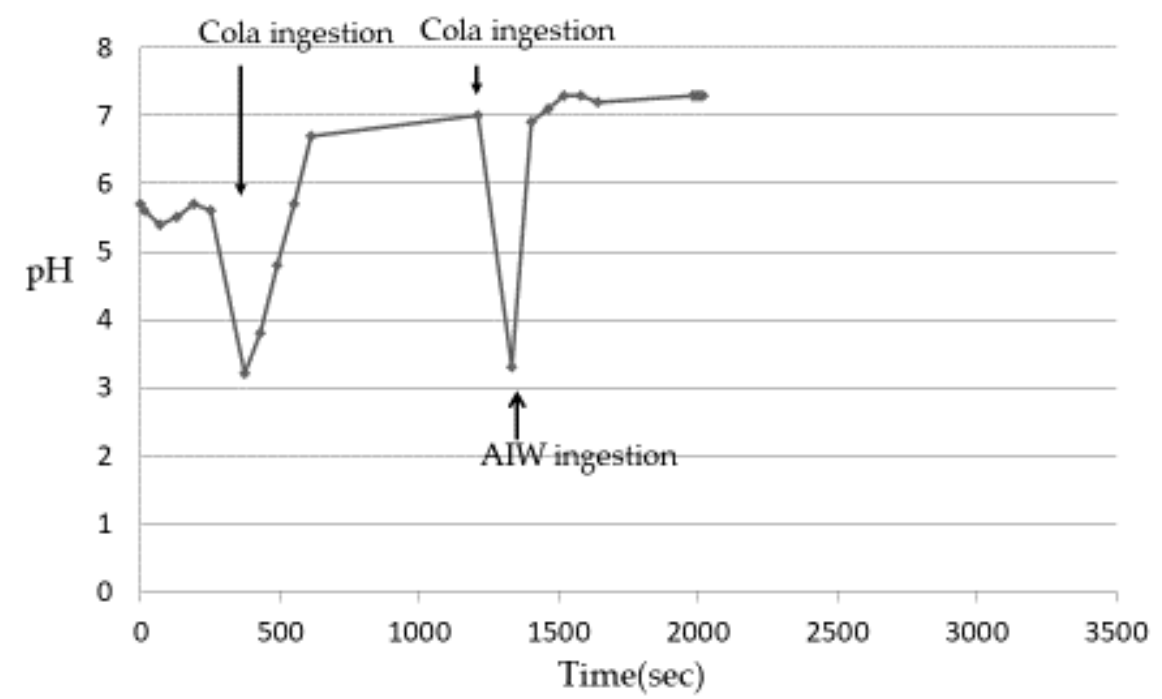

Figure 3. Changes in Es pH after ingestion of cola or AIW (alkaline ionized water) (Subject ID:4) [17]. 


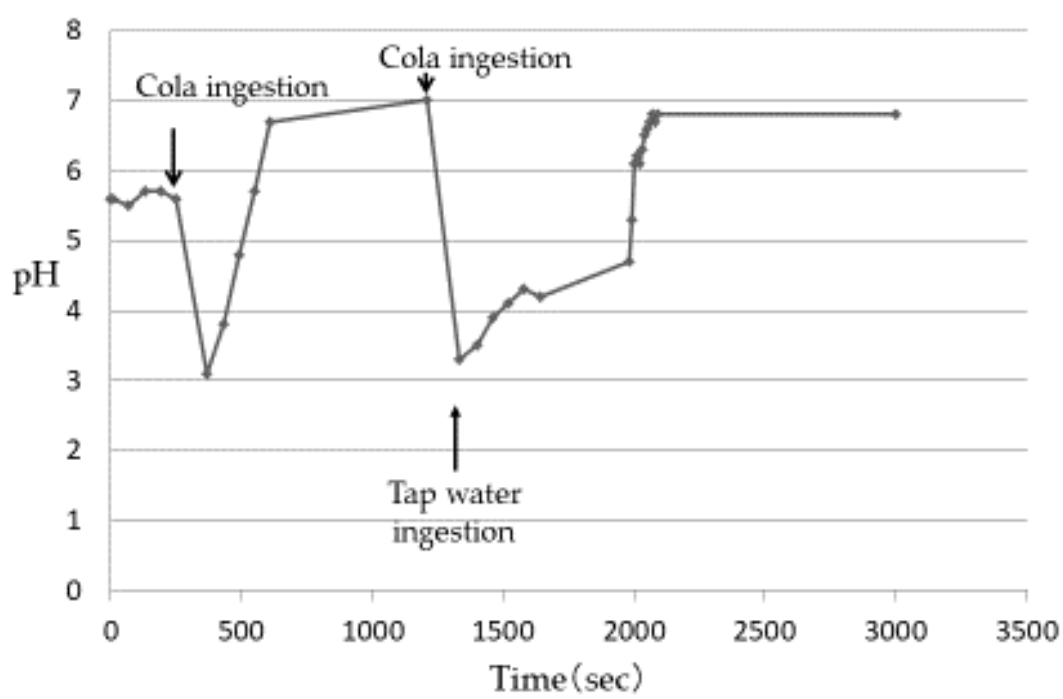

Figure 4. Changes in Es pH after ingestion of cola or Tap water (Subject ID:4) [17].

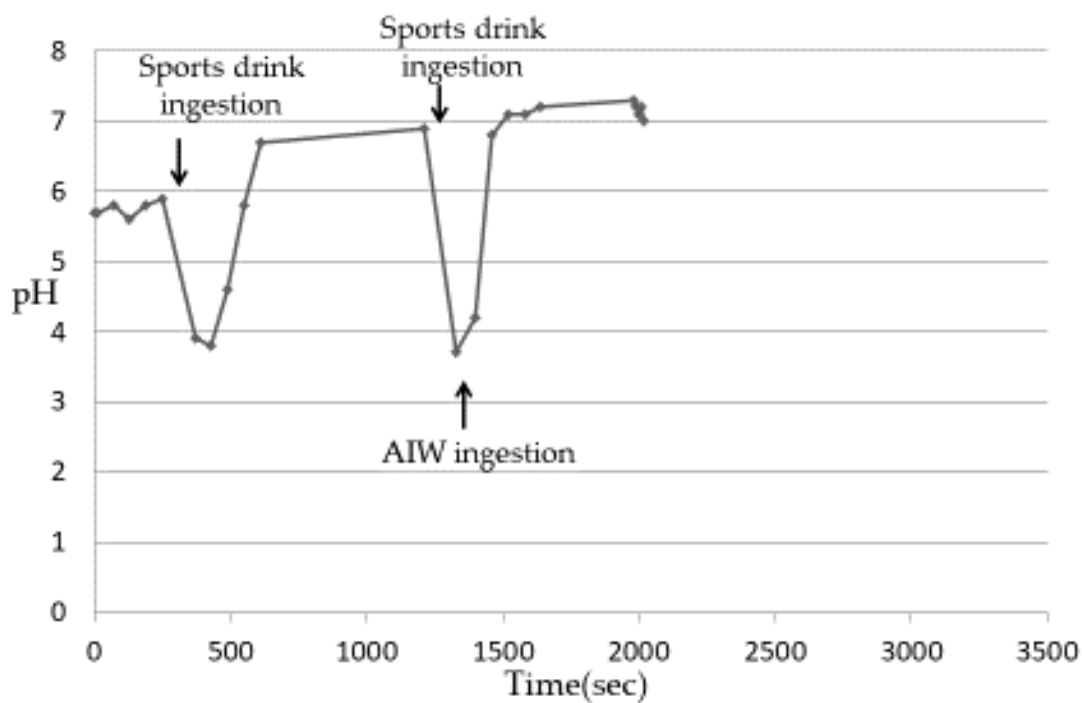

Figure 5. Changes in Es pH after ingestion of sports drink or AIW (Subject ID:4) [17].

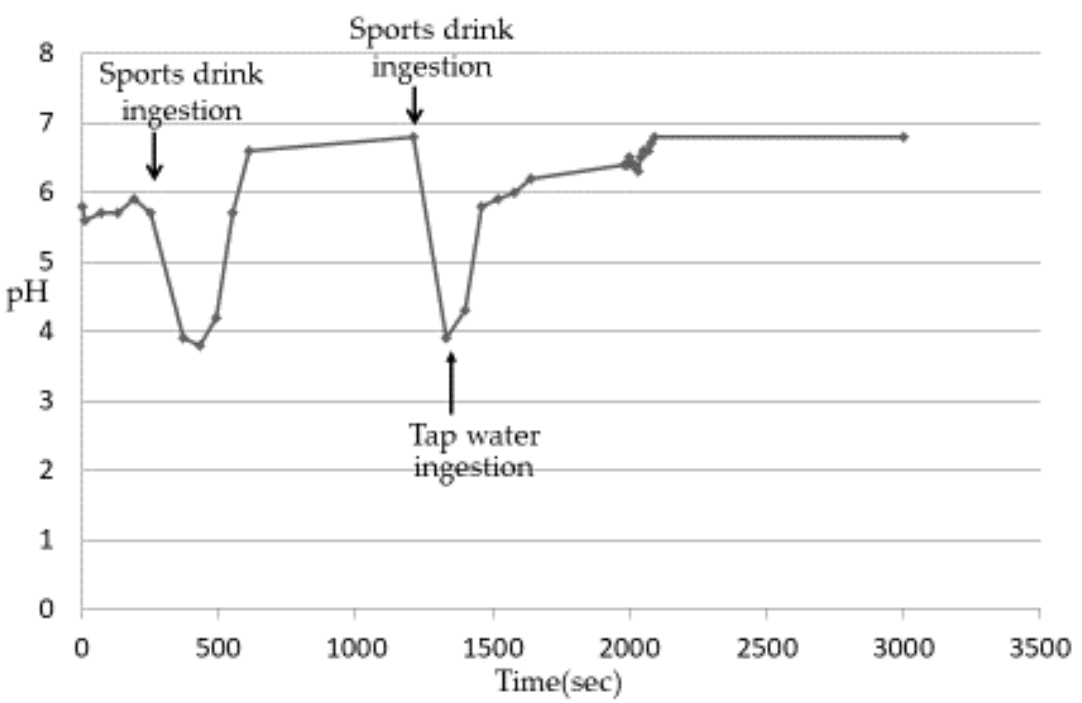

Figure 6. Changes in Es pH after ingestion of sports drink or Tap water (Subject ID:4) [17]. 
Table 2. Es $\mathrm{pH}$ (the $\mathrm{pH}$ of the enamel surface) with the subjects at rest [17].

\begin{tabular}{cc}
\hline Subject ID & $\mathbf{p H}$ (Median) \\
\hline 1 & 5.5 \\
2 & 5.2 \\
3 & 5.8 \\
4 & 5.7 \\
5 & 5.9 \\
\hline
\end{tabular}

\section{Es pH after Ingesting Acid Beverages and AIW}

The acidic beverages used in the experiments were cola and a sports drink, with $\mathrm{pH}$ values of 2.2 and 3.3, respectively. The method of ingestion of the acidic beverage involved the subject keeping $50 \mathrm{~mL}$ of it in their mouth while the $\mathrm{pH}$ electrode was attached to the surface of the enamel and then swallowing the beverage after swishing it around the oral cavity. For the ingestion of the AIW, when the Es $\mathrm{pH}$ reached the lowest value after ingesting the acidic beverage, the $\mathrm{pH}$ electrode was removed from the tooth surface, and $50 \mathrm{~mL}$ of the AIW was immediately ingested in the same manner as for the acidic beverage. After ingesting the AIW, the $\mathrm{pH}$ electrode was placed on the tooth surface again, and the $\mathrm{pH}$ was continuously measured. Measurements were also made using tap water ( $\mathrm{pH}$ 6.7) instead of AIW.

After ingesting cola, the Es pH of 5 subjects decreased from 3.1 to 3.3 (Table 3) and then gradually increased. Although the rate of $\mathrm{pH}$ increase was different among the subjects, it was confirmed that the plateau was almost reached in all the subjects after about 6-8 min. The $\mathrm{pH}$ at the time of reaching the plateau was close to 7 in all subjects, which was higher than the $\mathrm{pH}$ before the ingestion of cola. This phenomenon was considered to be due to the buffer capacity of saliva released after being stimulated by ingesting beverages [13-15]. When the increase in the Es $\mathrm{pH}$ reached a plateau, the change in the Es $\mathrm{pH}$ was measured when cola was ingested again and then the AIW was ingested. The Es pH decreased after the ingestion of the acidic beverages but increased rapidly with the subsequent ingestion of the AIW (Figure 3). Then, in all the subjects, the $\mathrm{pH}$ was close to 7 after about 10-20 s. In an experiment using tap water instead of AIW, the re-elevation of the Es $\mathrm{pH}$ was slower than that of the AIW, and it took about 9-12 min to reach approximately pH 7 (Figure 4). The Es $\mathrm{pH}$ after ingesting the sports drink decreased from 3.5 to 3.9 (Table 3 ) and then gradually increased. Similar to cola, the rate of the $\mathrm{pH}$ rise was different in the subjects but almost reached a plateau after about 10-12 min. The $\mathrm{pH}$ at the time of reaching the plateau was close to 7 in all subjects, which was higher than the $\mathrm{pH}$ before the ingestion of the sports drink. When the Es $\mathrm{pH}$ reached the plateau, the change in the Es pH was measured when the sports drink was ingested and then the AIW was ingested. As a result, as in the case of cola, the Es pH decreased after the ingestion of the sports drink but increased rapidly with the subsequent ingestion of the AIW (Figure 5). All subjects exhibited a pH close to 7 after about 15-20 s, following which a plateau was reached. In the experiment using tap water instead of AIW, the re-increase in the Es $\mathrm{pH}$ was gradual, similar to cola, and it took about $12-15 \mathrm{~min}$ to reach approximately $\mathrm{pH} 7$ (Figure 6). Since almost the same pattern was observed in all the subjects with respect to the change in the Es $\mathrm{pH}$ when ingesting the acidic beverage or AIW shown above, only the data for subject ID 4 are presented.

Table 3. Decrease in Es pH after ingestion of beverage [17].

\begin{tabular}{ccc}
\hline Subject ID & Cola & Sports Drink \\
\hline 1 & 3.1 & 3.9 \\
2 & 3.1 & 3.6 \\
3 & 3.2 & 3.5 \\
4 & 3.1 & 3.6 \\
5 & 3.3 & 3.8 \\
\hline
\end{tabular}




\section{Discussion}

The $\mathrm{pH}$ of the acidic beverages used in our experiment was 2.2 for cola and 3.3 for the sports drink. Since the critical $\mathrm{pH}$ of enamel decalcification is considered to be approximately 5.5-5.7 [5-8], acidic beverages will increase the likelihood of dental erosion or enamel demineralization/decalcification. In recent years, hydration with sports drinks has been widely recommended to prevent heat stroke and dehydration, and people of all ages consume sports drinks in Japan. Therefore, it is believed that the risk of dental erosion will increase in the future. It is important to note the frequency and number of intakes of acidic beverages in order to prevent dental erosion. In particular, since it is considered that the decrease in the Es $\mathrm{pH}$ directly indicates the risk of developing dental erosion, it is necessary to promptly increase the Es $\mathrm{pH}$ that is decreased by the ingestion of acidic beverages. In our study, the degree of the decrease in the $\mathrm{Es} \mathrm{pH}$ after ingestion and the rate of the subsequent increase were different between cola and the sports drink. That is, the Es $\mathrm{pH}$ was lower in cola at $\mathrm{pH} 2.2$ than in the sports drink with $\mathrm{pH}$ 3.3. Based on this finding, we believe that the degree of the decrease in the Es $\mathrm{pH}$ after the ingestion of the acidic beverage was related to the $\mathrm{pH}$ of the beverage. The $\mathrm{Es} \mathrm{pH}$, which decreased with the ingestion of cola or the sports drink, subsequently increased and reached a plateau at a value close to 7 in all subjects. The $\mathrm{pH}$ value of 7 is higher than the $\mathrm{pH}$ before the ingestion of the acidic drink, and we believe this was because the stimulation by the acidic drink temporarily promoted saliva secretion and the increased saliva came into contact with the enamel. We observed this when the Es $\mathrm{pH}$ decreased due to the ingestion of the acidic beverages; the Es $\mathrm{pH}$ increased rapidly following AIW ingestion. This increase was also observed when tap water was ingested but at a slower rate than that of the AIW. Therefore, when ingesting an acidic beverage, it is believed that the continuous ingestion of AIW afterward is effective in preventing dental erosion. It was also observed that the rate of increase in the Es $\mathrm{pH}$ by the AIW was slower for the sports drink than for cola. Although the cause is unclear, it has been reported that the pattern of changes in the Es $\mathrm{pH}$ due to acidic beverages differs depending on the type of beverage [4]. Moreover, this difference seems to be important in assessing the risk of an erosive effect on teeth. That is, the risk of dental erosion may be higher with sports drinks than cola. In the future, we plan to add other acidic beverages and further investigate the changes in the Es $\mathrm{pH}$ and the effects of AIW on them when they are ingested.

In this paper, we described the preventive effect of AIW on dental erosion; however, it is also known that AIW is effective at improving oral flora $[18,19]$ and intestinal flora $[20,21]$. Therefore, AIW may contribute to reducing the risk of diseases associated with these flora.

\section{Conclusions}

We investigated the effectiveness of alkaline ionized water (AIW) in preventing the occurrence of dental erosion caused by acidic beverages. We confirmed that the Es $\mathrm{pH}$, which was lowered by the ingestion of cola or a sports drink, was rapidly increased by the ingestion of AIW. Therefore, AIW was shown to be useful in preventing dental erosion caused by acidic beverages. We recommend the intake of a sufficient amount of AIW after ingesting acidic foods and drinks.

Author Contributions: Conceptualization, T.S. and K.S.; Methodology, T.S., S.K. and Y.T.; Formal analysis, T.S.; Investigation, T.S. and M.S.; Writing—original draft preparation, T.S.; writing-review and editing, K.S. and Y.F.; Visualisation, T.S. and H.T.; Supervision, Y.F.; Project administration, T.S. All authors have read and agreed to the published version of the manuscript.

Funding: AIW research was funded by Functional Water Foundation.

Conflicts of Interest: The authors declare no conflict of interest. 


\section{References}

1. Michael, W.J.D.; James, S.W. The developing caries lesion. In Primary Preventive Dentistry, 4th ed.; APPLETON \& LANGE: Stamford, CT, USA, 1995; pp. 39-60.

2. Tuominen, M.; Tuominen, R.; Ranta, H. Association between acid fumes in the work environment and dental erosion. Scand. J. Work Environ. Health 1989, 15, 335-338. [CrossRef] [PubMed]

3. Kitasako, Y.; Sasaki, Y.; Takagaki, T.; Sadr, A.; Tagami, J. Age-specific prevalence of erosive tooth wear by acidic diet and gastroesophageal reflux in Japan. J. Dent. 2015, 43, 418-423. [CrossRef] [PubMed]

4. Mizukami, S.; Sato, T. Study on the correlation between changes in enamel surface $\mathrm{pH}$ before and after soft drink ingestion on saliva flow volume, $\mathrm{pH}$, and buffer capacity. J. Nippon Dent. Univ. College Tokyo 2015, 6, 113-119, (English Abstract).

5. Ericsson, Y. Enamel-apatite solubility. Investigations into the calcium phosphate equilibrium between enamel and saliva and its to dental caries. Acta Odontol Scand. 1949, 8 (Suppl. 3), 1-139.

6. Ericsson, Y.; Oberg, H. A nomogram for the determination of saliva. Acta Odontol. Scand. 1952, 10, 67-70. [CrossRef] [PubMed]

7. Anderson, P.; Hector, M.P.; Rampersad, M.A. Critical pH in arresting and stimulated whole saliva in groups of children and adults. Int. J. Paediatr. Dent. 2001, 11, 266-273. [CrossRef] [PubMed]

8. Dawes, C. Why is the critical pH and why dose a tooth dissolve in acids? J. Can. Dent. Assoc. 2003, 69, 722-724. [PubMed]

9. Tanaka, Y. Structure and function of alkaline ionized water apparatus. J. Funct. Water 2017, 12, 29-34, (English Abstract).

10. Tashiro, H.; Kitabora, T.; Fujiyama, Y.; Bammba, T. Clinical evaluation of alkaline-ionized water for chronic diarrhea: Placebocontrolled double-blind study. Dig. Absorpt. 2001, 23, 52-56, (English Abstract).

11. Sato, T.; Suzuki, M.; Inaba, D.; Sakurai, S. Usefulness of alkaline ionized water to oral health: Investigation of the effect of AIW on remineralization of enamel lesion and on cariogenic bacteria. J. Funct. Water 2017, 13, 28-29, (English Abstract).

12. Kichuel, K.P.; David, W.B. Caries activity testing. In Primary Preventive Dentistry, 4th ed.; APPLETON \& LANGE: Stamford, CT, USA, 1995; pp. 302-305.

13. Drizen, S.; Mann, A.W.; Cline, J.K.; Spies, T.D. The buffer capacity of saliva as a measure of dental caries activity. J. Dent. Res. 1946, 25, 213. [CrossRef]

14. Sellman, S. The buffer value of saliva and its relation to dental caries. Acta Odontol. Scand. 1950, 8, 244. [CrossRef] [PubMed]

15. Helm, J.F.; Dodds, W.J.; Hogan, W.J.; Soergel, K.H.; Egide, M.S.; Wood, C. Acid neutralizing capacity of human saliva. Gastroenterology 1981, 83, 69. [CrossRef]

16. Sato, T.; Suzuki, M.; Kamoi, H. Evaluation of dental caries risk by measuring the pH of the enamel surface. J. Jpn. Acad. Oral Human Dock 2016, 11, 14-20, (English Abstract).

17. Suzuki, M.; Sato, T.; Kamoi, H.; Oshima, Y.; Kumazawa, Y. Basic study on the prevention of tooth ersion due to acidic beverages using alkaline ionized water. J. Jpn. Acad. Oral Human Dock 2017, 12, 26-30, (English Abstract).

18. Sato, T.; Suzuki, M.; Koike, M. Application of alkaline ionized water to oral care. J. Funct. Water 2015, 11, 45-46, (English Abstract).

19. Sato, T.; Suzuki, M. Study of the usefulness of alkaline ionized water for oral health. Part I Ultramorphological study on Porphyromonas gingivalis exposed to alkaline ionized water. J. Jpn. Soc. Oral Health Sci. 2018, 9, 26-31, (English Abstract).

20. Kiuchi, M.; Tanaka, Y.; Higashimura, Y.; Baba, Y.; Naito, Y.; Koyama, K. Effects of alkaline electrolyzed water on intestinal environment and stool characteristics in human. In Proceedings of the 18th Annual Meeting of JSFW Program and Abstracts, Osaka, Japan, 19 May 2019; Volume 54. (English Abstract).

21. Hayakawa, T.; Kato, N.; Fukuyama, H.; Eto, S.; Inagaki, M.; Nakamura, K.; Suzuki, T.; Shimada, M.; Nakagawa, T. Involvement of nickel in diet in the in vivo anti-oxidative effect of alkaline-electrolyzed water and hydrogenated water, and effect of these test waters on intestinal microbiota. In Proceedings of the 18th Annual Meeting of JSFW Program and Abstracts, Osaka, Japan, 19 May 2019; Volume 55. (English Abstract). 